\title{
Mass Spectra of Aromatic Hydrocarbons Filtered from Smoky Air ${ }^{1}$
}

\author{
Fred L. Mohler, Paul Bradt, and Vernon H. Dibeler
}

\begin{abstract}
Public health service chemists collected particulate matter from smoky air and separated aliphatic and aromatic hydrocarbons from this material. These samples have been analyzed by two methods. In one method the sample is slowly evaporated from a tube furnace directly into the mass spectrometer and spectra recorded as the temperature is increased step by step. In the other method the sample is completely vaporized in a heated reservoir and the vapor passed through a leak into the mass spectrometer. Mass spectra of the aliphatic compounds are not reported in detail. Mass spectra of the aromatic fractions evaporated from the tube furnace show sharply defined fractionation with molecule ions of fused-ring aromaties predominant. Compounds containing three to seven fused rings are tentatively identified. The mass spectrum from the reservoir mass spectrometer was recorded at ionizing voltages of $70 \mathrm{v}$ and at a low voltage, which gives predominantly molecule ions. The fused-ring aromatics include compounds that are carcinogenic.
\end{abstract}

\section{Introduction}

The Sanitary Engineering Center of the Public Health Service in Cincinnati, Ohio, has collected particulate matter from smoky air by drawing air through a glass filter. Hydrocarbons are dissolved out of the filter by an appropriate solvent, and aromatic compounds are separated from aliphatic and alicyclic compounds in a silica gel column. The solvent is then evaporated away at a temperature of $60^{\circ} \mathrm{C}$. These samples have been submitted to the Bureau's Mass Spectrometry Section for study. The prolonged drying at $60^{\circ} \mathrm{C}$ evaporates away the lighter hydrocarbons, and the residues are mixtures of heavy hydrocarbons with molecular weight in excess of about 160 . The smoky air samples were collected in London, England, and in St. Bernard, which is an industrial area near Cincinnati, Ohio. Coal smoke is probably predominant in both localities.

The following generalizations can be made about analysis of heavy hydrocarbon mixtures. In heavy aliphatic compounds the molecule ion peaks are always very small (of the order of 1 percent in $n$-paraffins and much smaller in branched compounds), and radical ions $\mathrm{C}_{4} \mathrm{H}_{9}^{+}, \mathrm{C}_{3} \mathrm{H}_{7}^{+}$, and $\mathrm{C}_{5} \mathrm{H}_{11}^{+}$ are usually the most abundant ions. In monocyclics the radical ions, $\mathrm{C}_{n} \mathrm{H}_{2 n-1}^{+}$are more abundant, in dicyclies $\mathrm{C}_{2} \mathrm{H}_{2 n-3}^{+}$, etc. Thus the mass spectra are indicative of the type of compounds in a mixture, but the molecular weights are not definitely determined.

In aromatic compounds the molecule ions are more abundant, and in polycyclic aromatics the molecule ion is by far the most abundant ion. Thus in a mixture of heavy aromatics the polycyclic aromatic compounds can be identified by their molecule ions. The mass spectra of isomeric polycyclics are quite similar, and it is not feasible to distinguish individual

1 This project was sponsored by the Department of Health, Education and Welfare. compounds where there are several isomers [1]. ${ }^{2}$

The mass spectrum at the customary ionizing voltages of 50 to $70 \mathrm{v}$ is a mixture of fragment ions and molecule ions. In the case of aromatic compounds the appearance potentials of fragment ions are $4 \mathrm{v}$ or more above the molecule ionization potentials. As the appearance potentials of molecule ions fall in a narrow range of less than a volt, it is possible to record a spectrum of the molecule ions alone at a low voltage of about $12 \mathrm{v}$ [2]. In the case of aliphatic mixtures this is not feasible because the appearance potentials of the more abundant fragment ions are often within a volt of the molecule ion appearance potentials.

\section{Experimental Procedure}

Two different techniques have been used to obtain the mass spectra of the aromatic fractions. In one method the sample is evaporated directly from a tube furnace into the ionization chamber of a mass spectrometer [3]. The sample of a few milligrams of material is in a small tube in direct contact with a thermocouple that measures the temperature of evaporation. The temperature is increased step by step, and at each step the mass spectrum is recorded. The observations on a sample extend over a period of 5 or 6 days. This gradual evaporation fractionates the sample, and this is an advantage in dealing with a complicated mixture. The method is not quantitative, however, as the ion currents depend on the magnitude of the step-by-step changes in temperature. Steps are graduated to keep ion currents of a convenient magnitude and fairly constant over the time required to record the spectrum. The mass spectrometer was a $60^{\circ}$ sector field instrument of 6 -in. radius of curvature, and the spectra were recorded by varying the magnetic field at a constant ion-accelerating voltage.

In the second method used the sample was in a reservoir held at a temperature that completely vaporized it and the vapor passed through a pinhole

2 Figures in brackets indicate the literature references at the end of this paper. 
leak into the mass spectrometer. The sample was introduced through a gallium-sealed valve into a 2liter reservoir held at $300^{\circ} \mathrm{C}$. A $180^{\circ}$ Consolidated gas analysis mass spectrometer recorded the spectrum by varying the ion-accelerating voltage. This is a standard method of analysis developed by $\mathrm{O}^{\prime} \mathrm{Neal}$ [4], and it could be made quantitative if pure compounds were available for calibration.

\section{Experimental Results}

\subsection{Aliphatic Fractions}

Samples from St. Bernard and from London were run in the tube-furnace mass spectrometer. The spectra show a long sequence of mass peaks with ions containing from 1 to 40 carbon atoms, and in general the intensity decreases progressively from the $\mathrm{C}_{4}$ group to the upper limit. The upper limit increases as the temperature is increased. Thus in the St. Bernard sample with the furnace at $83^{\circ} \mathrm{C}$ the spectrum extended to mass $404, \mathrm{C}_{29} \mathrm{H}_{54}$. At $125^{\circ}$ $\mathrm{C}$, the limit was mass $500, \mathrm{C}_{36} \mathrm{H}_{68}$; and at $163^{\circ} \mathrm{C}$, the limit was mass $540, \mathrm{C}_{39} \mathrm{H}_{72}$. In the lower and intermediate mass range, ions of formulas $\mathrm{C}_{n} \mathrm{H}_{2 n+1}$, $\mathrm{C}_{n} \mathrm{H}_{2 n-1}$, and $\mathrm{C}_{n} \mathrm{H}_{2 n-3}$ are the more abundant ions. In the London sample alkyl radical ions, $\mathrm{C}_{n} \mathrm{H}_{2 n+1}$, are more abundant than in the St. Bernard sample. These mass spectra are not reported in $\mathrm{de}^{-}$ tail, as they give no specific evidence as to the chemical composition.

\subsection{Aromatic Fractions}

The aromatic fractions were run both in the tubefurnace mass spectrometer and in the mass spectrometer with a heated reservoir. In contrast to the aliphatic samples, when the aromatic samples are slowly evaporated from the tube furnace there are striking changes in the mass spectrum as the temperature is increased step by step.

Table 1 lists the larger mass peaks in the mass spectra of the aromatic fraction from London smoke.

TABLE 1. Selected peaks in the mass spectra of the London aromatic fraction

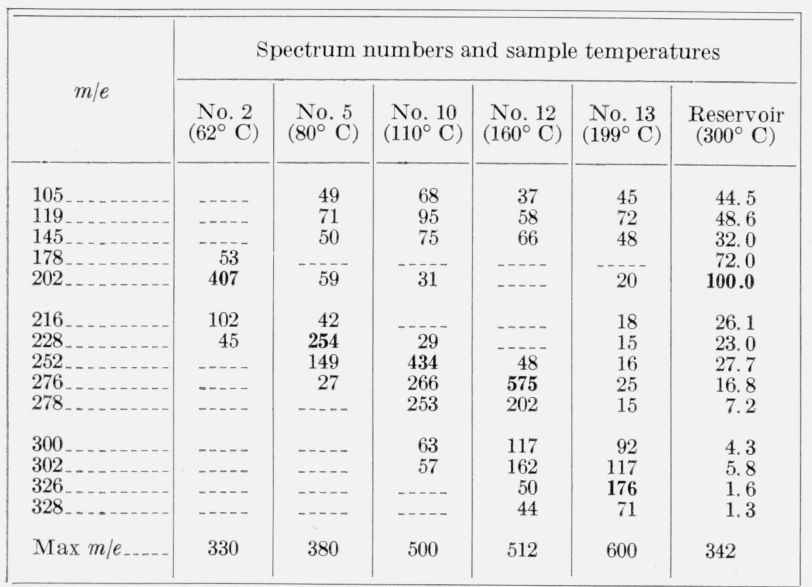

In the tube-furnace experiment, 25 mass spectra were recorded over a period of 6 days. In columns 2 to 6 of table 1 the larger peaks in five of these spectra are listed. The sample reached a temperature of $62^{\circ} \mathrm{C}$ without external heating, and the temperature was increased stepwise to $488^{\circ} \mathrm{C}$, but there were no significant changes above $326^{\circ} \mathrm{C}$. There were small peaks at almost every mass number, and the upper mass limit ranged from 330 at $62^{\circ} \mathrm{C}$ to over 600 at the higher temperatures. The upper mass limits of the spectra are given in the last row of the table. Columns 2 to 6 give ion currents in units of scale divisions on the most sensitive scale used. The last column gives the mass spectrum of the vapor in a reservoir at about $300^{\circ} \mathrm{C}$, and ion currents are relative to mass 202 taken as 100 .

Table 2 gives mass spectra obtained with the St. Bernard aromatic fraction. The arrangement of data is the same as in table 1, and the same mass peaks are reported. In this experiment, 19 spectra were recorded over a period of 5 days. Spectra 2, 6, 9 , and 12 were obtained on successive days, and 13 was recorded on the same day as 12 . In the St. Bernard sample the ions of mass 105, 119, and 145 are more abundant than in the London sample. In other respects the spectra are similar.

TABLE 2. Selected peaks in the mass spectra of the St. Bernard aromatic fraction

\begin{tabular}{|c|c|c|c|c|c|c|}
\hline \multirow{2}{*}{$m / e$} & \multicolumn{6}{|c|}{ Spectrum numbers and sample temperatures } \\
\hline & $\underset{\left(57^{\circ} \cdot \stackrel{2}{\mathrm{C}}\right)}{\text { No. }}$ & $\underset{\left(74^{\circ} \cdot \mathrm{C}\right)}{\text { No. } 6}$ & $\begin{array}{l}\text { No. } 9 \\
\left(118^{\circ} \mathrm{C}\right)\end{array}$ & $\begin{array}{c}\text { No. } 12 \\
\left(143^{\circ} \mathrm{C}\right)\end{array}$ & $\begin{array}{c}\text { No. } 13 \\
\left(211^{\circ} \mathrm{C}\right)\end{array}$ & $\begin{array}{c}\text { Reservoir } \\
\left(300^{\circ} \mathrm{C}\right)\end{array}$ \\
\hline $105_{\ldots}$ & 148 & 154 & 182 & 34 & -..-- & 25.6 \\
\hline $119 \ldots$ & 151 & 190 & 370 & 63 & ..... & 48.6 \\
\hline $145 \ldots$ & 129 & 230 & 520 & 90 & 53 & 67.3 \\
\hline $178 \ldots$ & 75 & 30 & 57 & 15 & -...- & 40.0 \\
\hline $202 \ldots$ & 354 & 73 & 78 & 15 & -...- & 100.0 \\
\hline $216 \ldots$ & 64 & 85 & 42 & 14 & -. & 28.9 \\
\hline 228 & 37 & 158 & 42 & 12 & $-\ldots$ & 34.6 \\
\hline 252 & 19 & 57 & 170 & 17 & & 20.2 \\
\hline 276 & 4 & 23 & 156 & 28 & 38 & 14.0 \\
\hline $278 \ldots$ & 4 & 25 & 78 & 15 & $\ldots-$ & 7.9 \\
\hline 300 & 8 & 60 & 36 & 86 & 101 & 8.9 \\
\hline & 5 & 32 & 52 & 115 & 103 & 10.7 \\
\hline $326 \ldots \ldots$ & 1 & 27 & 31 & 37 & 192 & 4.0 \\
\hline $328 \ldots \ldots \ldots$ & 3 & 46 & 31 & 27 & 96 & 4. 7 \\
\hline $\operatorname{Max} m / e \ldots$ & 330 & 399 & 460 & 549 & 574 & 436.0 \\
\hline
\end{tabular}

An experiment was tried with the London aromatic sample, using an ionizing voltage near the threshold for molecular ionization. The heatedreservoir mass spectrometer was used, and the results are presented in table 3 . The ionizing voltage was set at $10 \mathrm{v}$, but the corrected voltage is probably about $12 \mathrm{v}$. The sensitivity was low but usable, as the most abundant ion of mass 202 gave a current of 60 scale divisions. All ions lighter than 167 were absent, and the only ions of odd mass number apart from $\mathrm{C}^{13}$ isotope peaks are $167,181,195$, and 209. This indicates that fragment ions have been largely eliminated from the spectrum, and the remaining ions of even mass number are probably molecule ions. 
TABLE 3. Mass spectrum of London aromatic fraction at 10-v ionizing voltage

Heated-reservoir mass spectrometer

\begin{tabular}{|c|c|c|c|c|c|}
\hline$m / e$ & $\begin{array}{c}\text { Relative } \\
\text { abundance }\end{array}$ & $\begin{array}{c}\text { Possible } \\
\text { identification }\end{array}$ & $m / e$ & $\begin{array}{l}\text { Relative } \\
\text { abundance }\end{array}$ & $\begin{array}{c}\text { Possible } \\
\text { identification }\end{array}$ \\
\hline 167 & 15. 0 & & 222 & 16.2 & $\mathrm{C}_{17} \mathrm{H}_{18}$ \\
\hline 170 & 11.1 & & 224 & 22.6 & $\mathrm{C}_{17} \mathrm{H}_{20}$ \\
\hline 178 & 64.6 & $\mathbf{C}_{14} \mathbf{H}_{10}$ & & & \\
\hline 180 & 7.8 & $\mathrm{C}_{14} \mathrm{H}_{12}$ & 226 & 17.5 & $\mathrm{C}_{17} \mathrm{H}_{22}$ \\
\hline 181 & 16.6 & ............... & 228 & 21.4 & $\mathbf{C}_{18} \mathbf{H}_{12}$ \\
\hline 182 & 14. 2 & $\mathrm{C}_{14} \mathrm{H}_{14}$ & $\begin{array}{l}230 \\
232\end{array}$ & $\begin{array}{l}19.6 \\
27.1\end{array}$ & $\mathrm{C}_{18} \mathrm{H}_{14}$ \\
\hline 184 & 18.6 & $\mathrm{C}_{14} \mathrm{H}_{16}$ & $\begin{array}{l}232 \\
234\end{array}$ & $\begin{array}{l}27.1 \\
21.7\end{array}$ & $\begin{array}{l}\mathrm{C}_{18} \mathrm{H}_{16} \\
\mathrm{C}_{18} \mathrm{H}_{18}\end{array}$ \\
\hline 190 & 9.9 & & & & \\
\hline 192 & 61.5 & $\mathrm{C}_{15} \mathrm{H}_{12}$ & 236 & 13.5 & $\mathrm{C}_{18} \mathrm{H}_{20}$ \\
\hline 194 & 14.4 & $\mathrm{C}_{15} \mathrm{H}_{14}$ & 238 & 17.4 & $\mathrm{C}_{18} \mathrm{H}_{22}$ \\
\hline 195 & 18.1 & & 240 & 10.9 & $\mathrm{C}_{18} \mathrm{H}_{24}$ \\
\hline 196 & 28.0 & $\mathrm{C}_{15} \mathrm{H}_{16}$ & 242 & 11.2 & $\mathrm{C}_{19} \mathrm{H}_{14}$ \\
\hline 198 & 19.8 & $\mathrm{C}_{15} \mathrm{H}_{18}$ & 244 & & $\mathrm{C}_{19} \mathrm{H}_{16}$ \\
\hline 202 & $\begin{array}{r}100.0 \\
17.8\end{array}$ & $\mathbf{C}_{16} \mathbf{H}_{10}$ & 246 & 17.4 & $\mathrm{C}_{19} \mathrm{H}_{18}$ \\
\hline 204 & 17.8 & $\mathrm{C}_{16} \mathrm{H}_{12}$ & 248 & 10.6 & $\mathrm{C}_{19} \mathrm{H}_{20}$ \\
\hline 206 & 54.4 & $\mathrm{C}_{16} \mathrm{H}_{14}$ & 250 & 9.0 & $\mathrm{C}_{19} \mathrm{H}_{22}$ \\
\hline 208 & 19.5 & $\mathrm{C}_{16} \mathrm{H}_{16}$ & 252 & 17.5 & $\mathrm{C}_{20} \mathrm{H}_{12}$ \\
\hline 209 & 13. 2 & & 254 & 9.3 & $\mathrm{C}_{20} \mathrm{H}_{14}$ \\
\hline 210 & 31.0 & $\mathrm{C}_{16} \mathrm{H}_{18}$ & & & \\
\hline 212 & 20.2 & $\mathrm{C}_{16} \mathrm{H}_{20}$ & $\begin{array}{l}256 \\
258\end{array}$ & $\begin{array}{l}8.9 \\
7.7\end{array}$ & $\begin{array}{l}\mathrm{C}_{20} \mathrm{H}_{16} \\
\mathrm{C}_{20} \mathrm{H}_{18}\end{array}$ \\
\hline 216 & 37.0 & $\mathrm{C}_{17} \mathrm{H}_{12}$ & 260 & 9.3 & $\mathrm{C}_{20} \mathrm{H}_{20}$ \\
\hline 218 & 32.2 & $\mathrm{C}_{17} \mathrm{H}_{14}$ & 266 & 6. 6 & $\mathrm{C}_{21} \mathrm{H}_{14}$ \\
\hline 220 & 32.7 & $\mathrm{C}_{17} \mathrm{H}_{16}$ & 276 & 7.8 & $\mathbf{C}_{22} \mathbf{H}_{12}$ \\
\hline
\end{tabular}

\section{Discussion}

In table 1 the most abundant ions in spectra 2 , $5,10,12$, and 13 are at masses 202, 228, 252, 276, and 326 , respectively. These could be fused-ring aromatics pyrene, $\mathrm{C}_{16} \mathrm{H}_{10}$; naphthacene, $\mathrm{C}_{18} \mathrm{H}_{12}$; benzpyrenes, $\mathrm{C}_{20} \mathrm{H}_{12} ;$ anthanthrene, $\mathrm{C}_{22} \mathrm{H}_{12} ;$ and benzanthanthrene, $\mathrm{C}_{26} \mathrm{H}_{14}$; or isomers of these compounds. In each case doubly-charged molecule ions are conspicuous, and spectra are consistent with the mass spectra of fused-ring aromatics published in the American Petroleum Institute tables of Mass Spectral Data [1]. Table 4 lists possible identifications of most of the peaks listed in tables 1 and 2 . This table repeats from tables 1 and 2 the relative intensities as recorded by the heated-reservoir mass spectrometer. There are alternative explanations of many of these peaks, and results do not prove that all these peaks are fused-ring polycyclic aromatics. The list includes compounds with 3 to 7 fused sixmembered rings, and in most instances there are several isomeric compounds of each mass number. Mass spectra of isomeric aromatics are in general quite similar, and it is not feasible to distinguish between isomers. Mass peaks 105, 119, and 145 are fragment ions from alkyl benzenes. These peaks, in contrast to the others in table 1, remain of comparable intensity as the temperature changes. This indicates that the fragment ions come from compounds with a wide range of molecular weights.

The mass spectra of the St. Bernard aromatic sample in table 2 are qualitatively like the London sample in table 1. The most conspicious difference is that the alkylbenzene fragment ions 105,119 , and 145 are much more abundant in the St. Bernard fraction. Also the ion of mass 302 is more abundant and is the most abundant ion in spectrum number 12

A comparison of the two samples can be made by
TABLE 4. Possible identifications of polycyclic aromatics

\begin{tabular}{|c|c|c|c|c|}
\hline \multirow{2}{*}{$m / e$} & \multirow{2}{*}{ Formulas } & \multicolumn{2}{|c|}{ Abundance } & \multirow{2}{*}{ Compounds } \\
\hline & & London & St. Bernard & \\
\hline $\begin{array}{l}178 \\
202 \\
216 \\
228 \\
252\end{array}$ & $\begin{array}{l}\mathrm{C}_{14} \mathrm{H}_{10} \\
\mathrm{C}_{16} \mathrm{H}_{10} \\
\mathrm{C}_{17} \mathrm{H}_{12} \\
\mathrm{C}_{18} \mathrm{H}_{12} \\
\mathrm{C}_{20} \mathrm{H}_{12}\end{array}$ & $\begin{array}{r}72.0 \\
100.0 \\
26.1 \\
23.0 \\
27.0\end{array}$ & $\begin{array}{r}40.0 \\
100.0 \\
28.9 \\
34.6 \\
20.2\end{array}$ & $\begin{array}{l}\text { Anthracene. } \\
\text { Pyrene. } \\
\text { Benzanthrene. } \\
\text { Naphthacene, etc. } \\
\text { Benzpyrenes, etc. }\end{array}$ \\
\hline $\begin{array}{l}276 \\
278 \\
300 \\
302 \\
326\end{array}$ & $\begin{array}{l}\mathrm{C}_{22} \mathrm{H}_{12} \\
\mathrm{C}_{22} \mathrm{H}_{14} \\
\mathrm{C}_{24} \mathrm{H}_{12} \\
\mathrm{C}_{24} \mathrm{H}_{14} \\
\mathrm{C}_{26} \mathrm{H}_{14}\end{array}$ & $\begin{array}{r}16.8 \\
7.2 \\
4.3 \\
5.8 \\
1.6\end{array}$ & $\begin{aligned} 14.0 \\
7.9 \\
8.9 \\
10.7 \\
4.0\end{aligned}$ & $\begin{array}{l}\text { Anthanthrene, etc. } \\
\text { Dibenzanthracenes, etc. } \\
\text { Coronene. } \\
\text { Dibenzpyrenes, etc. } \\
\text { Benzanthanthrenes. }\end{array}$ \\
\hline 328 & $\mathrm{C}_{26} \mathrm{H}_{16}$ & 1.3 & 4. 7 & Anthraceno anthracene. \\
\hline
\end{tabular}

comparing mass spectra obtained with the reservoir mass spectrometer in table 4 .

In comparing spectra obtained with the tubefurnace mass spectrometer and the reservoir mass spectrometer it is to be noted that sensitivity of the former instrument operated at constant voltage increases as the molecular weight increases. The sensitivity of the other instrument operated at constant magnetic field tends to decrease. A recent paper reports a quantitative measurement of a known mixture of polyphenyls made with the tube-furnace spectrometer [3].

The low-voltage mass spectrum of table 3 presumably records molecule ions (except for the four peaks of odd mass number). The boldfaced mass peaks are peaks listed in tables 1 and 2 and are ascribed to fused-ring aromatics. The other peaks are interpreted as molecules derived by adding hydrogen or methyl radicals to these aromatics. The empirical formulas in the last column are derived on this assumption, but there are in most cases alternative possibilities. Because of the low sensitivity at low voltage, ions heavier than 276 were not detected in this experiment.

\section{Conclusions}

Results of table 3 indicate that there are at least 39 molecule ions in the limited mass range from 178 to 276 that is covered. The aromatic residues recovered from air are very complicated mixtures, and it is of interest that when these mixtures are slowly evaporated from the tube furnace, a few of the fusedring compounds stand out conspicuously and can be identified. This is because the slow evaporation affords an effective fractionation of the mixture and because the mass spectrometer has exceptionally high sensitivity for fused-ring aromatic molecule ions.

The occurence of these fused-ring aromatics in smoky air is a matter of significance because some compounds of this class are carcinogenic. 3,4Benzpyrene and 1,2-5,6-dibenzanthracene are known to be strongly carcinogenic [5], and it was recently found [6] that 3,4-9,10-dibenzpyrene is one of the most potent of the carcinogenic agents. Several other fused-ring aromatics are considered to be carcinogenic, and some alkyl derivatives are strongly carcinogenic. 
Benzpyrenes of molecular weight 252 give the most abundant molecule ion in spectrum 10 of table 1 and spectrum 9 of table 2. Dibenzpyrenes and other isomers of molecular weight 302 become most abundant in spectrum 12 of table 2 , and dibenzanthracenes of molecular weight 278 are of comparable abundance. Although the mass spectra cannot distinguish between isomers, results indicate that carcinogenic compounds are probably present in appreciable quantities in smoky air. The formation of fused-ring aromatics seems to be associated with the formation of smoke when either solid or liquid fuels are burned [7].

\section{References}

[1] Am. Petrol. Inst. Catalog of Mass Spectral Data, Serial numbers 958,959,1017, 1018, 1019, 1020, 1022, and 1237.

[2] F. H. Field and S. H. Hastings, Anal. Chem. 281248 (1956).

[3] Paul Bradt and Fred L. Mohler, J. Research NBS 60, 143 (1958) RP2831.

[4] M. J. O'Neal and T. P. Weir, Anal. Chem. 23830 (1951).

[5] Erich Clar, Aromatische Kohlenwasserstoffe, (Polycyclische systeme) (Berlin, Springer Verlag, 1941).

[6] Lacassagne, Zajdela, Buu-Hoi and Chalvet. Compt. rend. 244 273 (1957).

[7] J. F. Thomas and M. Mukai, Arch. Ind. Health 13567 (1956).

Washington, January 20, 1958. 